\title{
Effects of Fruit Maturity on Physicochemical Properties, Sugar Accumulation and Antioxidant Capacity of Wild Harvested Kakadu Plum (Terminalia ferdinandiana) ${ }^{\dagger}$
}

\author{
Anh Dao Thi Phan 1,2,*, Maral Seidi Damyeh 1,2, Saleha Akter 1,2, Mridusmita Chaliha ${ }^{1,2}$, Michael E. Netzel 1,2, \\ Daniel Cozzolino ${ }^{1,2}$ and Yasmina Sultanbawa ${ }^{1,2}$
}

Citation: Phan, A.D.T.; Damyeh, M.S.; Akter, S.; Chaliha, M.; Netzel, M.E.; Cozzolino, D.; Sultanbawa, Y. Effects of Fruit Maturity on Physicochemical Properties, Sugar Accumulation and Antioxidant Capacity of Wild Harvested Kakadu Plum (Terminalia ferdinandiana). Proceedings 2021, 70, 48. https://doi.org/ 10.3390/foods_2020-07819

Published: 10 November 2020

Publisher's Note: MDPI stays neutral with regard to jurisdictional claims in published maps and institutional affiliations.

Copyright: (C) 2021 by the authors. Licensee MDPI, Basel, Switzerland. This article is an open access article distributed under the terms and conditions of the Creative Commons Attribution (CC BY) license (http://creativecommons.org/licenses /by/4.0/).
1 ARC Industrial Transformation Training Centre for Uniquely Australian Foods, Queensland Alliance for Agriculture and Food Innovation, The University of Queensland, Coopers Plains, QLD 4108, Australia; s.maral@uq.edu.au (M.S.D.); saleha.akter@uq.edu.au (S.A.); mridusmitachaliha1@gmail.com (M.C.); m.netzel@uq.edu.au (M.E.N.); d.cozzolino@uq.edu.au (D.C.); y.sultanbawa@uq.edu.au (Y.S.)

2 Centre for Nutrition and Food Sciences, Queensland Alliance for Agriculture and Food Innovation, The University of Queensland, St. Lucia, QLD 4072, Australia

* Correspondence: a.phan1@uq.edu.au

† Presented at the 1st International Electronic Conference on Food Science and Functional Foods, 10-25 November 2020; Available online: https://foods_2020.sciforum.net/.

\begin{abstract}
Terminalia ferdinandiana (Kakadu plum), belonging to the family Combretaceae, is endemic to Australia and has a long history of traditional medicinal applications and food cuisine by the Australian Indigenous people. This study investigated the effects of maturity stages on the morphology, physicochemical parameters (total soluble solids (TSS), total acid content (TAC), and pH), soluble sugar profile and antioxidant capacity of Kakadu plum (KP) fruits that were wild harvested from different trees and classified into four different maturity stages (immature to mature). TSS and TAC were determined by standard assays/procedures, main sugars by UHPLC-MS/MS and antioxidant capacity (total phenolic content (TPC) and DPPH free radical scavenging capacity) by spectrophotometry. The results showed that soluble sugars (glucose, sucrose and fructose) ranging from 1.3 to $17.7 \%$ dry weight (DW), TSS (17.0-52.7\% DW) and TAC (1.3-6.7\% DW) increased with maturity. However, antioxidant capacity (TPC in the range of $7.4-21.9 \%$ DW and DPPH free radical scavenging capacity from 22 to $76 \%$ inhibition at the extract concentration of $20 \mathrm{~g} \cdot \mathrm{L}^{-1}$ ) did not follow the same trend as the one observed for soluble sugars, TSS and TAC. These differences were associated with the tree-to-tree variability as a consequence of the wild harvest condition. This study provides important information to both the KP industry and Indigenous enterprises regarding the selection of the appropriate maturity stage to harvest KP fruit to target for different markets (e.g., low-sugar vs. high-sugar fruit).
\end{abstract}

Keywords: Terminalia ferdinandiana; Kakadu plum; sugar profile; maturity

Supplementary Materials: The following are available online at www.mdpi.com/2504-3900/70/1/48/s1, poster presentation.

Institutional Review Board Statement: Not applicable.

Informed Consent Statement: Not applicable.

Data Availability Statement: Not applicable. 